European Association for the Development of Renewable Energies,

Environment and Power Quality
International Conference on Renewable Energies and

Power Quality (ICREPQ'10)

Granada (Spain), 23th to 25th March, 2010

\title{
Grid manager design using Battery Energy Storage Systems in weak power systems with high penetration of wind energy
}

\author{
A. Goikoetxea ${ }^{1}$, J. A. Barrena ${ }^{1}$, M. A. Rodríguez ${ }^{2}$, G. Abad ${ }^{1}$ \\ ${ }^{1}$ Faculty of Engineering, University of Mondragon, Loramendi 4, 20500 Mondragon, Spain, e-mail: \\ a.goikoetxea@eps.mondragon.edu, jabarrena@eps.mondragon.edu,gabad@eps.mondragon.edu \\ ${ }^{2}$ Ingeteam Transmission \& Distribution, S.A., Protección y control de redes eléctricas - C/ Usausuaga, 7 Pol. \\ Artunduaga48970 Basauri (Bizkaia) - Spain, e-mail: miguelangel.rodriguez@ingeteam.com
}

\begin{abstract}
The increasing penetration of renewable energies is becoming a problem for the stability of the grid and the planning of electricity generation. The use of batteries in parallel to wind farms can be a very interesting issue in order to assure controlled power delivery of renewable energy sources. In this way wind energy can become in a predictable and even controllable energy resource.

This article presents a proposition to design a grid manager for weak power systems with high penetration of wind energy using Battery Energy Storage Systems (BESS). Using power demand and wind predictions this system manager will send reference power to BESS and controllable generators. In this way the primary power reserve can be reduced and wind deviations will not affect to the performance of generators.
\end{abstract}

\section{Key words:}

Wind energy, Battery Energy Storage Systems, Constant Power Delivery, load leveling

\section{Introduction}

Historically one of the main problems of electricity generation is the necessity to meet the electricity demand instantaneously. Due to the impossibility to store large amounts of electricity the electric power production should be sized to meet the peak demand. In this way the relation between power production capacity and produced power is very low, around $40-50 \%$.

This low capacity factor of electrical grids is turning lower with the impact of renewable energies, such as solar and wind energy. Many times these renewable resources produce their peak power when the consumption is very low, while sometimes there is not any renewable power during peak consumption periods. By storing energy from variable resources, such as wind and solar power, electricity storage could provide firm generation from these units, allow the produced energy to be used more efficiently $[1,2]$.

The impact of load leveling on reducing transmission and distribution (T\&D) losses it has been analyzed in recent years [3], these studies show that the capture of renewable production to deliver when transmission capacity is available, using electricity storage systems can improve the transmission capacity factor for renewable sources.
The storage and latter delivery of renewable energy can be a very valuable solution in order to meet the demand of a certain area with the power consumption of this area. In this way the renewable could be fully consumed reducing the use of fossil fuels and the power transmission losses are reduced because the power is consumed on site.

The use of batteries in parallel to wind farms has been analyzed in previous articles. The control of the Battery Energy Storage System (BESS) to control the active and reactive power supply of a wind farm [4], as well as the contribution of BESS to the relation between integration of wind farms and voltage stability limits [5] were analyzed. Also the possible economical benefits for a wind farm owner were analyzed [6].

Furthermore the power constancy of a wind farm can be a very interesting issue for grid operators, since uncertainties are reduced in order to plan the power production. Grid operators should assure several ancillary services and safe, secure and reliable operation of the interconnected power system [7]. In this way the constant power delivery of wind farm helps on the control of frequency, reducing the necessary power reserve in each moment. The primary power reserve is the reserve of generators to respond in the face of power variations, the need of this reserve increases due to the variability of wind power. In this context the owners of wind farms can negotiate a special contract if they are able to ensure constant power delivery in advance.

The aim of this article is the specification of an operation algorithm for a grid manager for weak electrical grids, with high penetration of wind energy. The aims of the grid manager are the reduction of the primary power reserve and the optimal performance of the conventional generators using Battery Energy Storage Systems (BESS) in parallel to a wind farm, in order to reduce the uncertainty due to wind power variation.

Depending on the prediction of wind and load demand the system manager will send references to the different generators and BESS every 10 minutes. The BESS will be controlled to absorb wind power variations and estimation errors. The required control algorithm in order to achieve this purpose will be designed. 


\section{Scenario for the study}

A weak simplified power system is analyzed with a single consumption node and several generation nodes, in order to analyze the contribution of a battery in parallel to a wind farm to reduce the primary power reserve. The power generation is composed by a main combined cycle power station, several diesel generators and a wind farm. The combined cycle power station has a nominal power of $10 \mathrm{MW}$, the diesel generators have $10 \mathrm{MW}$ and the wind farm has 10MW of nominal power. A $2 \mathrm{MW}$ Battery Energy Storage System (BESS) is in parallel to the wind farm.

In this scenario conventional (combined cycle and diesel) generators are able to meet the maximum power demand, in this way the power supply is assured even during periods without wind power production.

A simplified electrical grid will be considered where all the elements are connected to the same node through impedance representing a line. The wind farm and BESS work as power station able to predict a constant power delivery for the next hour. In this way the primary power reserve is reduced to the uncertainty of the power demand.

In this scenario the wind farm operator sends the information about the next hour power production of the wind farm and the grid operator sets the reference power for the conventional power sources, the primary power reserve of these generators will meet the difference between the real and predicted power demand.

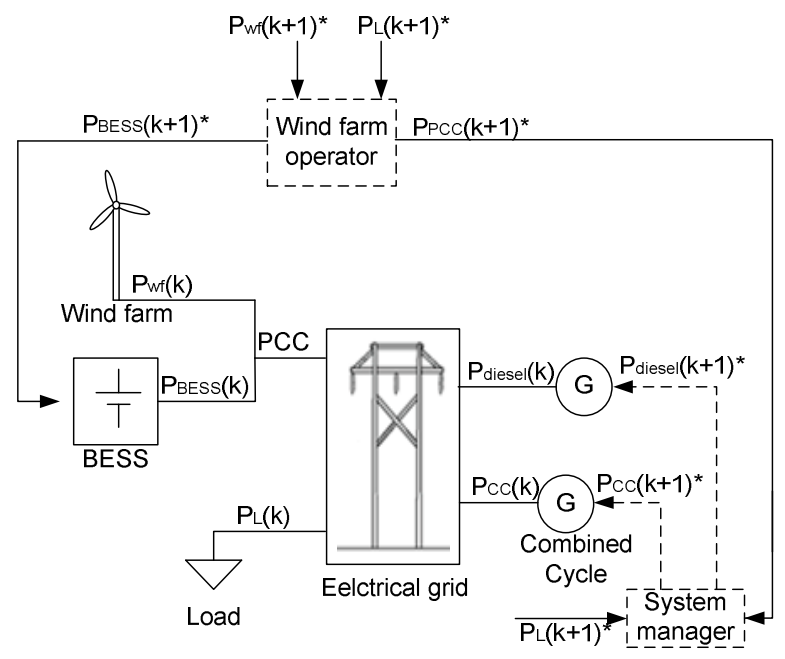

Figure 1: Scenario proposed for the study

\section{System modeling}

The system will be modeled to be analyzed using dynamic Power Flow Analysis. The power flow algorithm based on Backward-Forward Sweep method [8] is implemented in a Simulink function in order to analyze the power system. The system's dynamic behavior will be analyzed regarding voltage and frequency profiles.

\section{A. Load}

In power flow simulations the load is a variable value of active and reactive power consumption (PQ node). The load demand curve given for a certain day in the Spanish electrical grid, with 10 minutes values, defines the load demand curve used for this analysis.

The real load profile is proportional to this load demand, but adding two different standard deviations. On the one hand the common deviation due to the connection and disconnection of domestic load with a standard deviation of $10 \mathrm{~kW}$, on the other hand the deviation due to industrial loads or mistakes in other considerations with a standard deviation of $300 \mathrm{~kW}$.

The former is created using random Gaussian error every simulation instant but filtered by a first order filter with a time constant of 2 seconds. The latter is also created by a random Gaussian error and a filter, but it is created every 10 minutes and the time constant of the filter is 200 seconds.

The forecasted load demand profile for the system manager is based on the same load profile with a standard deviation of $100 \mathrm{~kW}$ every ten minutes.

\section{B. Wind farm}

The wind farm will be considered as a variable value of active and reactive power, but with negative active power. The power production is dependent on the wind profile. The active and reactive power supplied by the wind farm will regard a look-up table with values of $\mathrm{P}$ and $\mathrm{Q}$ for certain wind speed and a first order input filter in order to simulate the kinetic/electrical energy transformation time constant (10 seconds). The wind power production starts from $4 \mathrm{~m} / \mathrm{s}$ and the maximum power production is achieved with a wind speed of 12.5 , the disconnection of the generator is necessary with a speed of $25 \mathrm{~m} / \mathrm{s}$.

The wind profile is defined by real wind measurements of 10 minutes mean values and standard deviation, of Monte Oiz wind farm. The typical deviation and maximum deviation of the same measured wind are used in order to create the wind profile for the wind farm. The temporal wind profile series are created filtering these mean values and adding frequency components and white noise based on the standard deviation $[9,10]$. The frequency components are considered for three blades wind turbines.

The forecasted wind profile is quite precise for ten minutes predictions with a mean error of $0.198 \mathrm{~m} / \mathrm{s}$ and a standard deviation of $0.181 \mathrm{~m} / \mathrm{s}$ [11], in this case a random error with this standard distribution will be added to the measured mean values in order to simulate a predicted wind profile.

\section{Battery Electricity Storage System}

The BESS will be modeled also as a PQ node with controllable $\mathrm{P}$ and $\mathrm{Q}$. The $\mathrm{Q}$ control loop will maintain the voltage constant, while the $\mathrm{P}$ control loop will absorb or deliver the necessary power to supply the constant power established for every 10 minutes period. The response of the BESS is modeled with a time constant of 2 seconds. The maximum power output is $2 \mathrm{MW}$.

The battery technology that will be chosen should be fast enough to respond in few seconds to the variations of the 
wind power generation. Regarding the largest BESS installations working in parallel to wind farms Vanadium Redox Flow batteries [12], valve-regulated lead-acid (VRLA) and Sodium Sulfur (NaS) [13] batteries are used in these kind of installations.

\section{Combined Cycle power station}

The combined cycle power station is modeled with the simplified model [14] shown in Figure 2.

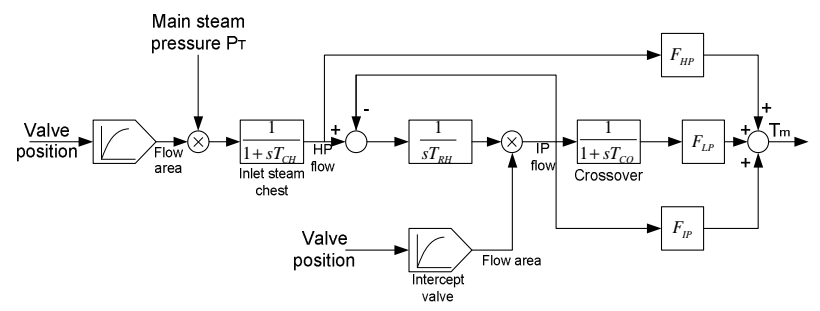

Figure 2: Simplified model for a Combined Cycle generator

The control of the generator is made by the governor shown in Figure 3.

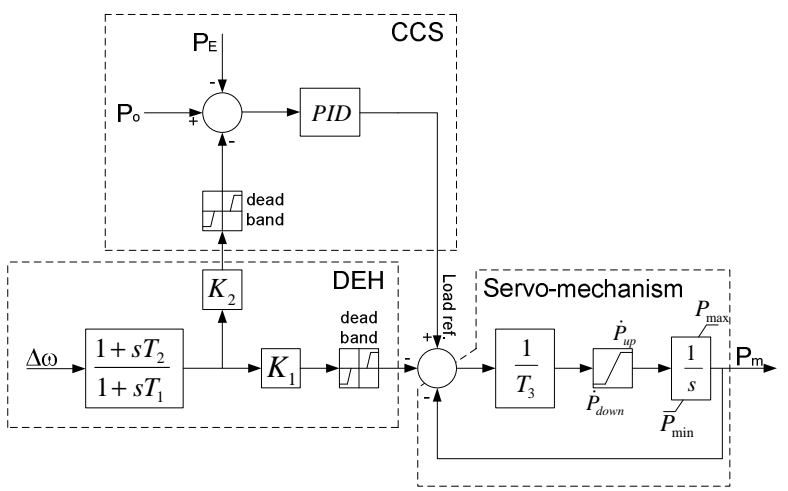

Figure 3: Block diagram of the governor

The power station will be considered as a single generator.

\section{E. Diesel power station}

The power station is composed by several diesel generators. Their dynamic behavior is taken into account in order to participate in the primary frequency regulation. In the dynamic power flow analysis the power station will be defined as a simplified with a Woodward governor, as shown in Figure 4 [15]. In this case 5 diesel generators of $2 \mathrm{MW}$ are considered.

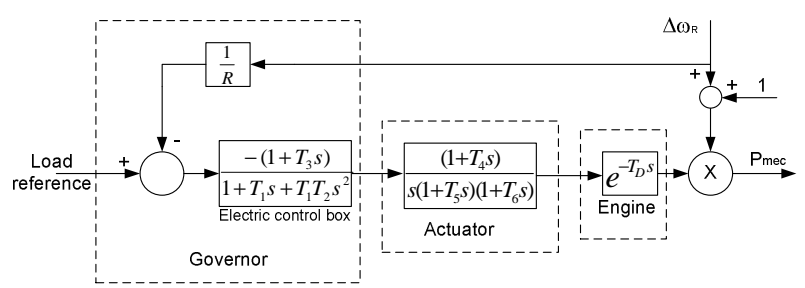

Figure 4: Simplified model for a diesel generator

\section{Primary power reserve}

As the utilities must always ensure the balance between generation and consumption they have to hold power reserve for unexpected load ramps, unit breakdowns and lack of primary energy. Due to technical and economic restraints this power reserve is divided into primary, secondary, and long-term reserve according to its activation time [16].

In a power system with high penetration of wind power the primary power reserve should be sized to respond the deviations of load consumption and wind power generation. In a small power system these deviations can be a very important part of the total installed power. This primary reserve should be fast to avoid large frequency deviations. Using a battery to absorb the variations of wind power the primary power reserve can be reduced to respond only to load deviations. In this case the instantaneous variation of the load is under $100 \mathrm{~kW}$ while the wind power variation can vary from maximum power production to zero in few seconds. Most of the instantaneous deviations of wind power are between $\pm 2 \mathrm{MW}$, so using a battery of this size most of the disturbance produced by the wind farm may be avoided.

Figure 5 shows the simulation of the system with and without battery. In the first graph are compared the wind power prediction and the real wind profile. In the second the real and forecasted load demand. While third and fourth graphs show the sharing of power generation with and without Battery Energy Storage System working in parallel to the wind farm, where Pdiesel, Pcc, Pwf and Pwf+bess are the power deliver of the diesel power station, Combined Cycle power station, wind farm and wind farm+BESS respectively. These graphs show that using a battery can be reduced the primary power reserve. But also that absorbing the power variations by the battery the performance of the different generators is improved working most of the time with nominal power. This makes the regulation of the system more predictable.
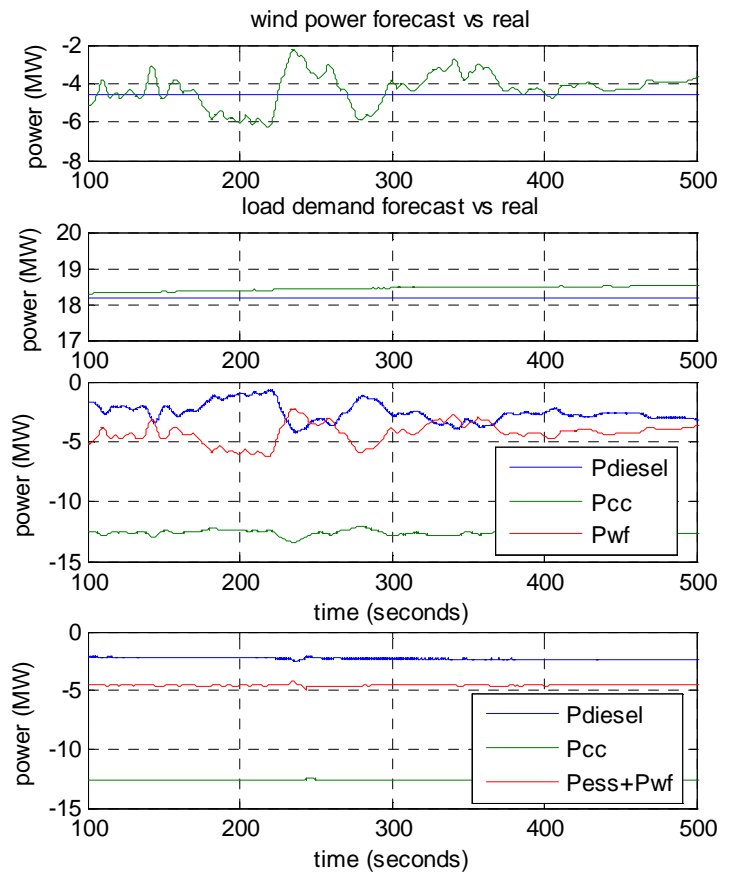

Figure 5: Comparison of the system behavior

\section{Operation strategy of the system manager}

The operation strategy should meet the power demand instantaneously using the active control devices of the 
system. In this case they are the BESS, the combined cycle power plant and the diesel power plant. Using ten minute predictions of load demand and wind profile the system manager sets the control references for the diesel and combined cycle power plants for the next period (10 minutes) $\mathrm{k}+1$.

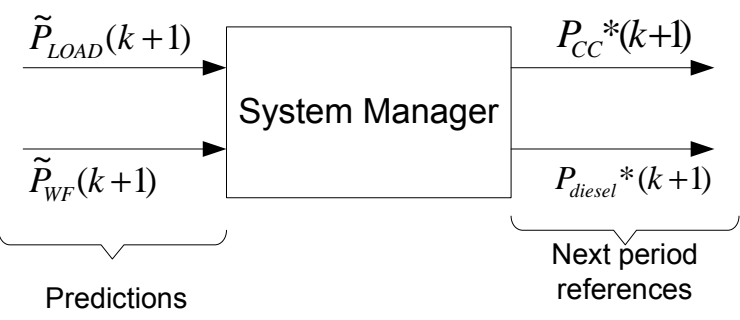

Figure 6: System manager

$$
\begin{array}{cc}
P_{C C} *(k+1)=-\widetilde{P}_{L O A D}(k+1)-\widetilde{P}_{W F}(k+1)+1 M W & \text { Eq. } 1 \\
P_{\text {diesel }} *(k+1)=-\widetilde{P}_{L O A D}(k+1)-\widetilde{P}_{W F}(k+1)-P_{C C} *(k+1) & \text { Eq. } 2
\end{array}
$$

During each period the diesel power station changes its load reference in order to keep constant the frequency.

$$
P_{\text {diesel }} *(k)=-\frac{K_{I}}{s} \cdot \frac{\Delta f}{R}
$$

The operation of the BESS aims to control the active power output in order to keep it constant during each period of ten minutes

\section{Power Flow Analysis}

The previously mentioned Power Flow algorithm, implemented in a Simulink function, calculates the load flows through the different lines and nodes of the system, every simulation step. The inputs of this function are the instantaneous power values of the different generators and the load demand. The outputs of the function are the voltage values at the nodes and the power losses through the lines. The sum of the different power inputs and the line losses is divided by the total inertia of the different generators to calculate the differential of the frequency. The integral of this value gives the frequency variation each simulation step.

Figure 7 shows 4 hours simulation from 10:00 to 14:00. In the first graph the predicted and real wind power for this period are shown, while in the second the real and predicted load demand profiles are shown. In the third graph are shown the power outputs of the different generators, considering the Wind Farm+BESS as a single generator. The fourth graph shows the State of Charge of the BESS. In this simulation the aim of the BESS is to absorb the variations of wind power.

Figure 8 shows the simulation of the same period but in this case the BESS stores energy from 00:00 to 12:00, to supply from 12:00 to 00:00. In these conditions $1 \mathrm{MW}$ is used to charge/discharge the battery. For these two cases the BESS technology could be different. For the first case Regenesys batteries or Flywheels can be used while for the second case a NaS battery system could be appropriate [13].
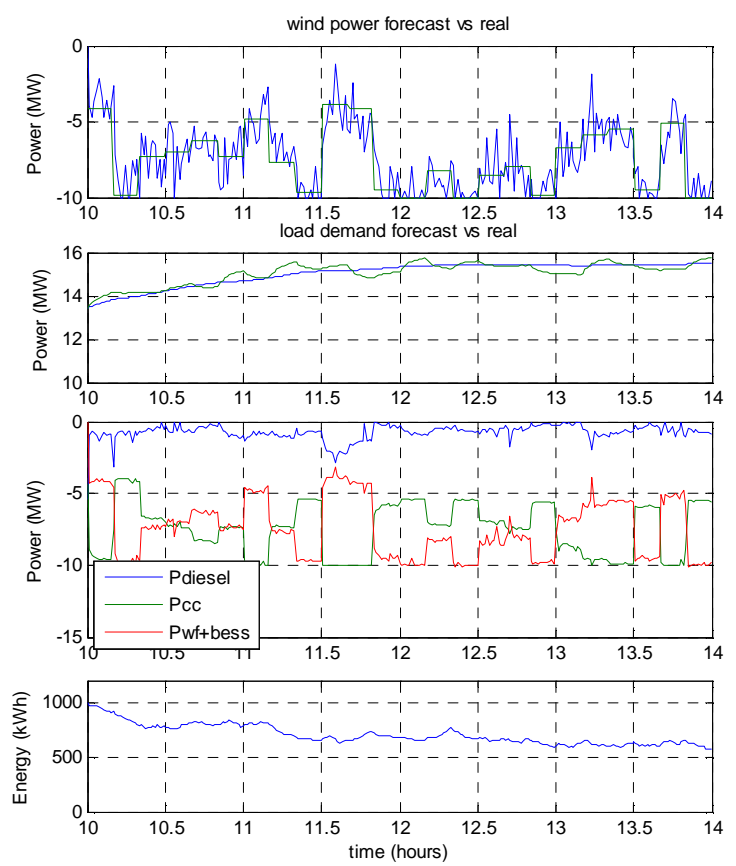

Figure 7: Power Flow simulations, case I
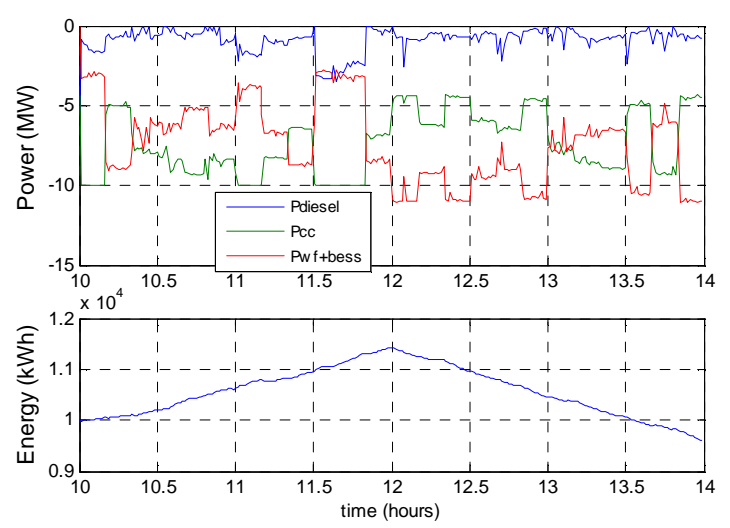

Figure 8: Power Flow simulations, Case II

\section{Conclusions}

The contribution of a BESS in parallel to a wind farm is a suitable solution in order to supply a predictable energy source. This solution can attenuate one of the main handicaps of wind energy, the strong variability. The wind power supply is still variable but the use of BESS gives the chance to plan the share of power generation in advance.

This is a very interesting solution for Grid Operators to reduce the Primary Power Reserve and also to plan the working conditions of the different generators in order to work in optimal conditions improving the performance of each generator.

Batteries or other storage devices together with variable loads will become mandatory to increase the penetration of renewable energies up to limits that nowadays are impossible to cover. 


\section{References}

[1] R. J. Thomas, "Putting an Action Plan in Place," in IEEE power\&energy magazine US: IEEE Power\&Energy Society (PES), 2009.

[2] Z. Lubosny and J. W. Bialek, "Supervisory Control of a Wind Farm," IEEE transactions on Power Systems, vol. 22, 2007.

[3] A. Nourai, V. I. Kogan, and C. M. Schafer, "Load Leveling Reduces T\&D Line Losses," IEEE transactions on Power Delivery, 2007.

[4] A. Goikoetxea, M. Rodriguez, H. Bindner, and A. Milo, "Design of control strategies to improve grid integration in fixed speed wind energy systems with battery storage," in ICREPQ 08 Santander, 2008.

[5] A. Goikoetxea, J. A. Barrena, M. A. Rodriguez, and G. Abad, "Active Substation Design to Maximize DG Integration," in PowerTech Bucharest (Romania), 2009.

[6] A. Goikoetxea, J. A. Barrena, M. A. Rodriguez, and G. Abad, "Benefits of distributed energy storage working in parallel to distributed energy resources," in ICREPQ Valencia (Spain), 2009.

[7] G. Verbič and F. Gubina, "Cost-Based Models for the Power-Reserve Pricing of Frequency Control," IEEE transactions on Power Systems, vol. 19, 2004.

[8] A. Milo, A. Martínez, M. Rodríguez, and A. Goikoetxea, "Dynamic power flow tool development for low voltage networks analysis with high penetration level of distributed generation," in ICREPQ 08 Santander, 2008.

[9] J. L. Rodríguez Amenedo, F. Rodríguez García, and J. C. Burgos Díaz, "Experimental rig to emulate wind turbines," in International Conference on Electrical Machines, Istambul, 1998.

[10] M. Santos, A. Milo, M. Rodríguez, and R. Reyero, "Comparison Of Dynamic Models For Wind Turbine Grid Integration Studies," in European Wind Energy Conference London, 2004.

[11] A. Kusiak, H. Zheng, and Z. Song, "Short-Term Prediction of Wind Farm Power: A Data Mining Approach," IEEE Transactions on Energy Conversion, vol. 24, 2009.

[12] L. Barote, R. Weissbach, R. Teodorescu, C. Marinescu, and M. Cirstea, "Stand-alone wind system with Vanadium Redox Battery energy storage," in Optimization of Electrical and Electronic Equipment Brasov, 2008.

[13] I. P. Gyuk, S. Eckroad, T. Key, and H. Kamath, "EPRI-DOE Handbook Supplement of Energy Storage for Grid Connected Wind Generation Applications," 2004.

[14] P. Kundur, Power System Stability and Control: McGrawHill, Inc., 1994.

[15] L. R. Manio, K. Kameda, J. J. Dai, H. Iki, K. Katayama, and Y. Uriu, "Sequential Motor Dynamic Acceleration and Reacceleration Simulations: Comparison of ETAP® and EMTP-RV® Software," in International Conference of Power Systems Transients Kyoto, 2009.

[16] D. Gundolf, "Power Reserve in Interconnected Systems with High Wind Power Production," in Power Tech Conference Porto, Portugal, 2009. 